\title{
Anti-metastatic effect of jolkinolide $B$ and the mechanism of activity in breast cancer MDA-MB-231 cells
}

\author{
CHAO SUN ${ }^{1}$, HONGXIA CUI ${ }^{1}$, HONGYAN YANG ${ }^{1}$, XIAOHUI DU ${ }^{1}$, LILING YUE ${ }^{2}$, JICHENG LIU ${ }^{2}$ and YU LIN ${ }^{1}$ \\ ${ }^{1}$ Department of Pharmacology; ${ }^{2}$ The Institute of Medicine, Qiqihar Medical University, \\ Qiqihar, Heilongjiang 161006, P.R. China
}

Received August 18, 2014; Accepted May 1, 2015

DOI: $10.3892 / \mathrm{ol} .2015 .3310$

\begin{abstract}
Tumor metastasis is the main cause of mortality in cancer patients. However, no effective therapies are currently available to prevent metastasis. Cell adhesion to the extracellular matrix (ECM) is crucial in cancer progression and metastasis. Thus, suppression of cell adhesion may be an effective therapeutic strategy for the prevention of metastasis. In the present study, the anti-adhesion and anti-invasion effects of jolkinolide B, a diterpenoid compound from Euphorbia fischeriana Steud, that were exerted through suppression of $\beta_{1}$-integrin expression and phosphorylation of focal adhesion kinase (FAK) were examined in human breast cancer MDA-MB-231 cells. Jolkinolide B inhibited the adhesion of MDA-MB-231 cells to fibronectin but not to poly-L-lysine. In addition, jolkinolide B inhibited extracellular signal-regulated kinase (ERK) phosphorylation. U0126, an ERK inhibitor, also suppressed the invasion and adhesion of MDA-MB-231 cells. Overall, the present data demonstrated that jolkinolide $\mathrm{B}$ is a novel inhibitor of FAK-mediated signaling pathways that is involved in decreasing cell adhesion and invasion. Mitogen-activated protein kinase/ERK kinase may play a critical role in these effects, indicating that jolkinolide B possesses therapeutic potential for the treatment of breast cancer metastasis.
\end{abstract}

\section{Introduction}

It is evident that metastasis underlies the lethality of cancer (1). Metastasis is a complicated, multi-step pathophysiological process that involves the movement of tumor cells from their primary location to a secondary site, in addition to the subsequent adhesion at the secondary site. Cell adhesion to the extracellular matrix (ECM) is critical and fundamental for the regulation of numerous physiological and pathological phenomena (2), including cancer cell invasion and migration. As

Correspondence to: Dr Yu Lin, Department of Pharmacology, Qiqihar Medical University, 333 Bukui North Street, Qiqihar, Heilongjiang 161006, P.R. China

E-mail: yulincn2014@126.com

Key words: jolkinolide B, integrin, MDA-MB-231 cell, adhesion a cell adhesion molecule, integrin participates in these cellular processes by mediating the adhesion of cells to the ECM and by transmitting signals that regulate these processes. Integrins are promising targets for the treatment of inflammatory and autoimmune diseases (3).

Integrins are a group of transmembrane proteins consisting of $\alpha$ and $\beta$ subunits that demonstrate non-covalent interactions. At least $18 \alpha$ - and $8 \beta$-subunits are able to form $>24 \alpha \beta$ integrin heterodimers $(4,5)$. The extracellular domain binds to the ECM, resulting in integrin activation and subsequent stimulation of signal transduction. Enzymes that are crucial in signal transduction, including focal adhesion kinase (FAK), are also recruited to adhesion sites (6).

FAK is a non-receptor tyrosine protein kinase that plays an instrumental role in the assembly of integrin signaling molecules (7). Several studies have reported that FAK is a regulator of cell adhesion and cell metastasis $(8,9)$. Therefore, targeting the adhesion signaling pathway that mediates numerous such signals has been a major goal in the effort to develop novel therapeutics.

In previous years, numerous natural plant ingredients possessing anticancer effects have received considerable attention in pharmacology studies. Jolkinolide B is a biologically active chemical isolated from Euphorbia fischeriana Steud. Previous studies have revealed that this chemical acts as an anticancer agent $(10,11)$. However, it is not clear whether jolkinolide B exerts anti-metastasis effects by suppressing the expression of adhesion molecules, such as $\beta_{1}$-integrin. Therefore, the present study evaluates the anti-metastatic role and mechanisms of jolkinolide B on breast cancer MDA-MB-231 cells in vitro.

\section{Materials and methods}

Cell line and cell culture. The human breast cancer cell line MDA-MB-231 and the other cancer cell lines used in the present study (U251, DU145, MGC803, K562, A549, Bcap37 and ACHN cells) were obtained from the Cell Bank of Type Culture Collection of the Chinese Academy of Sciences (Shanghai, China). The cells were cultured in L15 medium (Gibco Life Technologies, Carlsbad, CA, USA) supplemented with $10 \%$ fetal bovine serum (Gibco Life Technologies) at $37^{\circ} \mathrm{C}$ in a $5 \% \mathrm{CO}_{2}$ atmosphere, and were digested with $0.25 \%$ trypsin.

Reverse transcription-polymerase chain reaction (RT-PCR). Total RNA was isolated from MDA-MB-231 cells using the 
TRIzol Reagent (Invitrogen, Carlsbad, CA, USA). Reverse transcription was performed with $2 \mu \mathrm{g}$ total RNA, random primers, and reverse transcriptase (Invitrogen) in a $25 \mu \mathrm{l}$ reaction volume. PCR was performed using Taq DNA polymerase. The following gene-specific primers were used for RT-PCR: $\beta_{1}$-integrin sense, 5'-ATGCCTACTTCTGCACGATG-3' and anti-sense, 5'-TCCTTTGCTACGGTTGGTTA-3'; and GAPDH sense, 5'-GCGCCTGGTCACCAGGGCTGCTT-3' and anti-sense, 5'-TGCCGAAGTGGTCGTGGATGACCT-3'. GAPDH was used as an internal control for mRNA integrity and equal loading in each sample. PCR conditions were as follows: 1 cycle of $95^{\circ} \mathrm{C}$ for $3 \mathrm{~min} ; 35$ cycles of $94^{\circ} \mathrm{C}$ for $30 \mathrm{sec}$, $53^{\circ} \mathrm{C}$ for $30 \mathrm{sec}$ and $72^{\circ} \mathrm{C}$ for $30 \mathrm{sec}$; and extension at $72^{\circ} \mathrm{C}$ for $2 \mathrm{~min}$. The PCR products were resolved in $1.5 \%$ agarose gels and the results were analyzed using MJ Opticon Monitor analysis software (version 3.1; Bio-Rad Laboratories, Hercules, CA, USA).

Cell adhesion assay. The cell adhesion assay was performed as previously described (12). First, the 96-well plates were coated with $100 \mu \mathrm{l} /$ well of $10 \mu \mathrm{g} / \mathrm{ml}$ fibronectin $(\mathrm{FN})$ or poly-L-lysine and incubated overnight at $4^{\circ} \mathrm{C}$. Non-specific binding sites were blocked with $0.2 \%$ bovine serum albumin for $1 \mathrm{~h}$ at $4^{\circ} \mathrm{C}$. The MDA-MB-231 cells were incubated with or without jolkinolide B at concentrations of $0.5,1$ and $2 \mu \mathrm{M}$ for $24 \mathrm{~h}$, or $10 \mu \mathrm{M}$ U0126 (Sigma-Aldrich, St. Louis, MO, USA), followed by resuspension in serum-free medium. The resuspended cells were plated in quadruplicate into wells and allowed to adhere for $2 \mathrm{~h}$ at $37^{\circ} \mathrm{C}$. Unattached cells were washed away and adherent cells were fixed with $4 \%$ paraformaldehyde for $15 \mathrm{~min}$ and stained with $0.5 \%$ crystal violet in $20 \%$ methanol for $10 \mathrm{~min}$. Subsequent to washing, dye was extracted using $10 \%$ acetic acid and quantified by measuring the absorbance at $570 \mathrm{~nm}$ on a microplate reader (Safire2; Tecan Group Ltd., Männedorf, Switzerland). The rate of adhesion was calculated using the following formula:

$$
\operatorname{Adhesion~}(\%)=\frac{\left(\mathrm{A} 570_{\text {Jolkinolide B }}-\mathrm{A} 570_{\text {blank }}\right)}{\left(\mathrm{A} 570_{\text {control }}-\mathrm{A} 570_{\text {blank }}\right)}
$$

Cell invasion assay. Cell invasion was tested in a Transwell chamber with $8-\mu \mathrm{m}$ pore membranes (EMD Millipore, Billerica, MA, USA). The plate was precoated with $30 \mu \mathrm{g} /$ well Matrigel (BD Biosciences, Franklin Lakes, NJ, USA). MDA-MB-231 cells were added into the upper chamber at a density of $3 \times 10^{5}$ cells $/ \mathrm{ml}$, with or without jolkinolide B. After $24 \mathrm{~h}$ incubation at $37^{\circ} \mathrm{C}$, the non-invading cells were removed from the upper surface of the filter. The invading cells on the lower surface were fixed with methanol for $10 \mathrm{~min}$, stained with $0.1 \%$ crystal violet for $20 \mathrm{~min}$, and washed three times with water. The stained cells were photographed under a fluorescence microscope and were dissolved in $10 \%$ acetic acid. The optical densities of each well were determined by measuring the absorbance at $570 \mathrm{~nm}$. The ratio of migration was calculated using the following formula:

$$
\operatorname{Migration}(\%)=\frac{\left(\mathrm{A} 570_{\text {Jolkinolide B }}-\mathrm{A} 570_{\text {blank }}\right)}{\left(\mathrm{A} 570_{\text {control }}-\mathrm{A} 570_{\text {blank }}\right)}
$$

Cell viability assay. Cell viability was assessed using an MTT assay. The MDA-MB-231 cells were seeded into 96-well plates at a density of $5 \times 10^{3}$ cells per well and treated with jolkinolide B at concentrations of $0.5,1$ and $2 \mu \mathrm{M}$ for $24 \mathrm{~h}$. Subsequently, $20 \mu \mathrm{l}$ of MTT solution was added in each well to yield a final concentration of $500 \mu \mathrm{g} / \mathrm{ml} \mathrm{MTT}$ and incubated continuously at $37^{\circ} \mathrm{C}$ for $4 \mathrm{~h}$. The medium was then removed and combined with $150 \mu \mathrm{l}$ dimethyl sulfoxide. The absorbance of each well was measured at $570 \mathrm{~nm}$ using a microplate reader (Safire2; Tecan Group Ltd.). Cell viability was determined as the percentage of viable jolkinolide B-treated cells compared with the untreated controls. The MTT assay was performed for three independent experiments.

Western blotting. Total protein from MDA-MB-231 cells was extracted using lysis buffer that consisted of $20 \mathrm{mM}$ Tris- $\mathrm{HCl}$ at pH 7.4, $0.2 \mathrm{mM}$ EDTA, $1 \mathrm{mM}$ EGTA, $50 \mu \mathrm{g} / \mathrm{ml}$ leupeptin, $250 \mathrm{mM}$ sucrose and $20 \mathrm{mM}$ phenylmethylsulfonyl fluoride. The cell lysates were centrifuged at $12,000 \mathrm{x}$ g for $20 \mathrm{~min}$ at $4^{\circ} \mathrm{C}$, and the protein concentration was determined using the bicinchoninic acid (BCA) protein assay kit (Beyotime Institute of Biotechnology, Haimen, Jiangsu, China) following the protocol provided by the manufacturer. Equal amounts $(40 \mu \mathrm{g})$ of protein samples were separated by SDS-PAGE and were transferred to a nitrocellulose filter membrane. The membrane was blocked with a solution of 5\% nonfat dry milk for $2 \mathrm{~h}$ at room temperature, followed by incubation overnight at $4{ }^{\circ} \mathrm{C}$ with the following primary antibodies: monoclonal mouse anti-human $\beta_{1}$-integrin (dilution, 1:500; cat. no. 9699S), monoclonal rabbit anti-human FAK (dilution, 1:1,000; cat. no. 13009), monoclonal rabbit anti-human phosphorylated FAK (dilution, 1:1,000; cat. no. 8556), monoclonal rabbit anti-human ERK (dilution, 1:1,000; cat. no. 8201S), monoclonal rabbit anti-human phosphorylated ERK (dilution, 1:1,000; cat. no. 8201S), monoclonal rabbit anti-human Akt (dilution, 1:1,000; cat. no. 8200S), monoclonal rabbit anti-human phosphorylated Akt (p-Akt; dilution, 1:1,000; cat. no. 8200S) and monoclonal rabbit anti-human GAPDH antibody (dilution, 1:5,000; cat. no. 2118S; all purchased from Cell Signaling Technology, Beverly, MA, USA). The membranes were incubated for an additional $2 \mathrm{~h}$ at room temperature with the respective horseradish peroxidase-conjugated goat anti-rabbit secondary antibody (dilution, 1:10000; ZSGB-BIO, Beijing, China). Subsequent to washing, the specific proteins were detected using an enhanced chemiluminescence western blotting kit (Amersham Biosciences, Piscataway, NJ, USA). GAPDH was used as an internal control to confirm that an equal quantity of protein was loaded into each lane.

Statistical analysis. The data were expressed as the mean \pm standard deviation and SPSS 13.0 statistical software (SPSS, Inc., Chicago, IL, USA) was used to perform an analysis of variance and unpaired Student's t-test. All experiments were repeated at least three times. Comparisons between the groups were performed using Kruskal-Wallis one-way analysis of variance. $\mathrm{P}<0.05$ was considered to indicate a statistically significant difference.

\section{Results}

Expression of $\beta_{1}$-integrin. To determine the expression pattern of mRNA and $\beta_{1}$-integrin protein levels in carcinoma cells, 
A
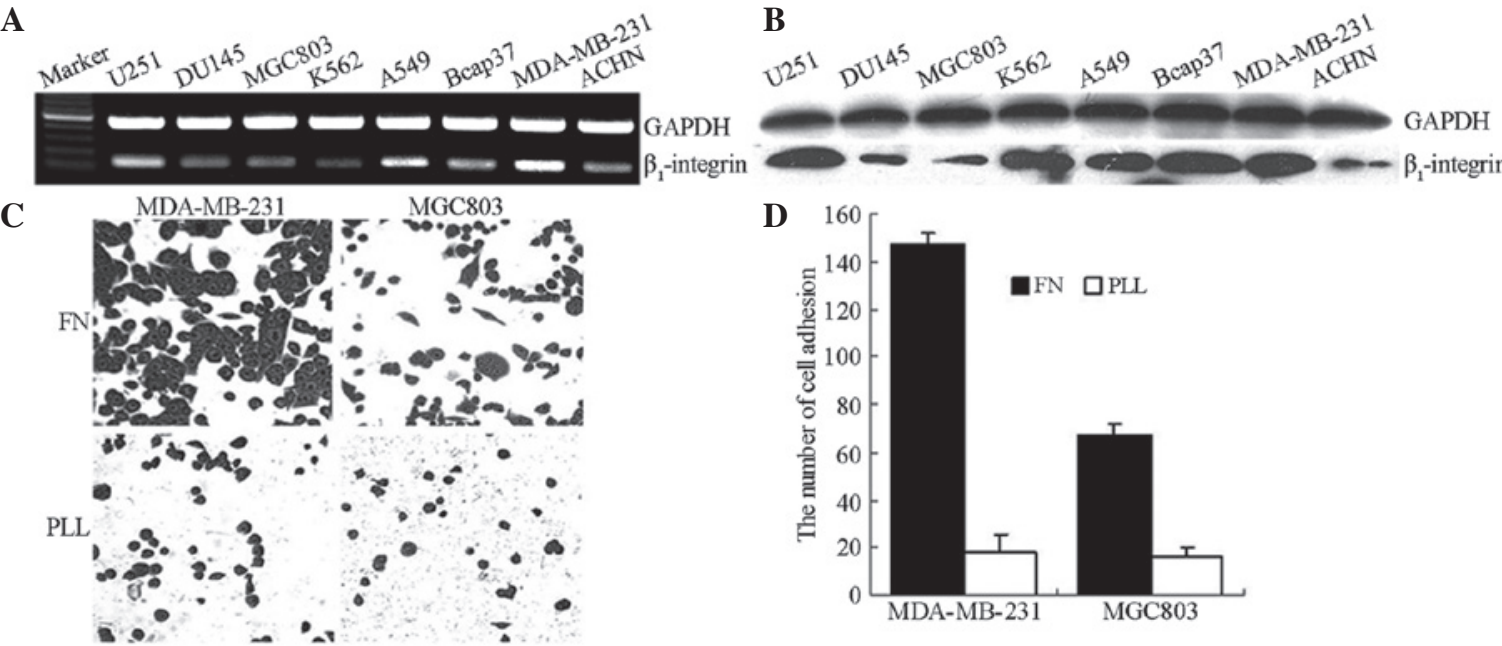

Figure 1. Expression of $\beta_{1}$-integrin in various cancer cell lines. (A) Reverse transcription-polymerase chain reaction for $\beta_{1}$-integrin mRNA expression. (B) Western blot analysis of $\beta_{1}$-integrin expression. (C) Adhesion of MDA-MB-231 and MGC803 cells to FN and PLL. FN, fibronectin; PLL, poly-L-lysine.
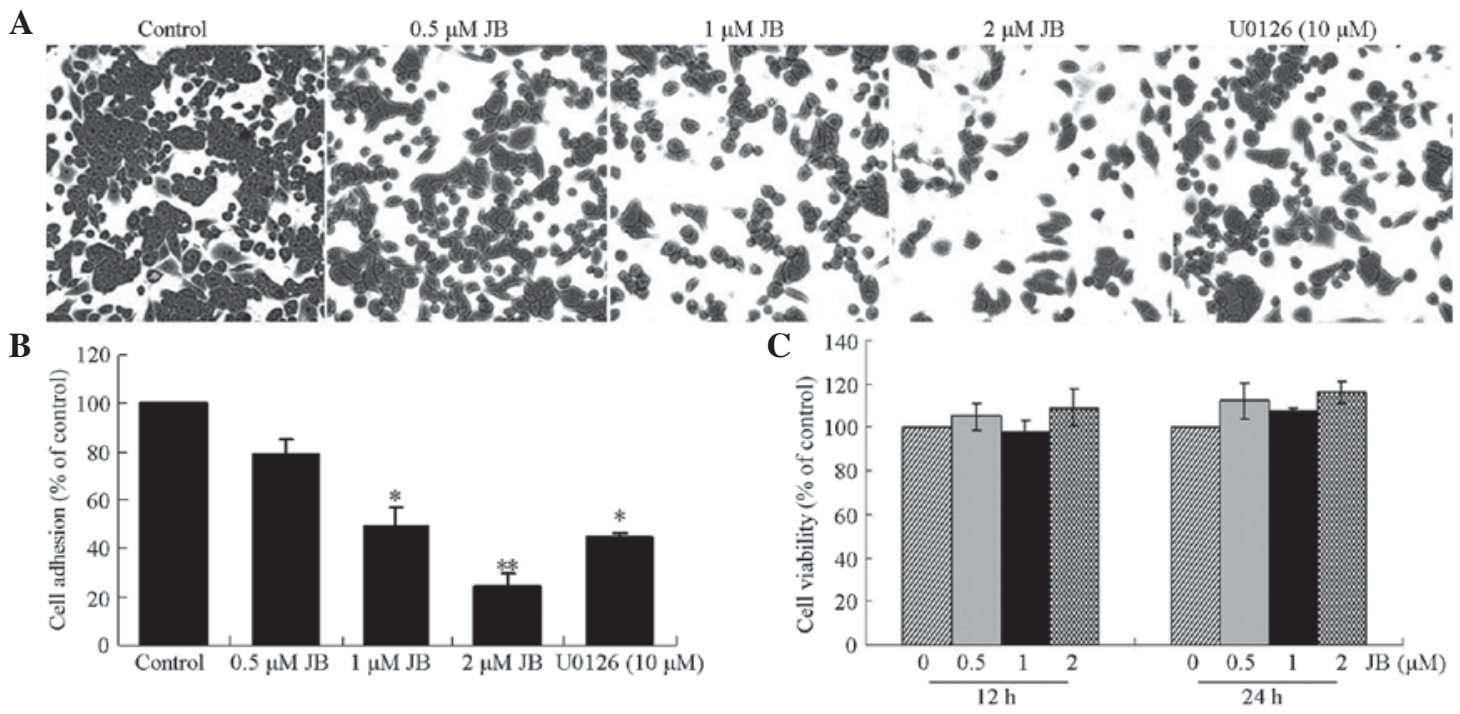

Figure 2. Effect of JB on the adhesion of MDA-MB-231 cells to FN. (A and B) JB inhibits the adhesion of MDA-MB-231 cells to FN. (C) Effect of JB on cell viability was determined by the MTT assay. FN, fibronectin; JB, jolkinolide B.

$\beta_{1}$-integrin expression was analyzed by RT-PCR and western blot analysis in eight different human cancer cell lines. As shown in Fig. 1A and B, an increased level of $\beta_{1}$-integrin mRNA and protein expression was detected in MDA-MB-231, U251 and A549 cells compared with the expression in MGC803, K562 and DU145 cells.

To investigate the association between $\beta_{1}$-integrin expression and the progression of cancer cell adhesion to the ECM in vitro, the adhesion ability of MGC803 and MDA-MB-231 cells with differing levels of $\beta_{1}$-integrin expression was determined. The results revealed that adhesion to $\mathrm{FN}$, a component of the ECM and a typical integrin ligand, was increased in MDA-MB-231 cells compared with the MGC803 cells. However, no difference was observed in the adhesion to poly-L-lysine, which does not associate with integrins (Fig. 1C).

Effect of jolkinolide $B$ on cell adhesion. To examine the effects of jolkinolide B on the adhesion of MDA-MB-231 tumor cells to FN and poly-L-lysine, a monolayer cell adhesion assay was performed. The results revealed that the ability of MDA-MB-231 cells to adhere to FN was significantly inhibited by 78,49 and $24 \%$ following the exposure of the cells to $0.5,1$ and $2 \mu \mathrm{M}$ jolkinolide $\mathrm{B}$, respectively. In addition, $10 \mu \mathrm{M}$ U0126, an ERK inhibitor, suppressed the adhesive ability of MDA-MB-231 cells ( $\mathrm{P}<0.05$; Fig. $2 \mathrm{~A}$ and $\mathrm{B})$. By contrast, cell adhesion to poly-L-lysine was not affected by jolkinolide $B$ treatment.

The cell viability was also assessed to determine whether the effect of jolkinolide B on cell adhesion was due to cytotoxicity. After 12 or $24 \mathrm{~h}$ of treatment with $0.5,1$ and $2 \mu \mathrm{M}$ jolkinolide B, the MDA-MB-231 cells were found to maintain a high level of viability (Fig. 2C).

Effect of jolkinolide B on invasion ability. A Transwell assay was performed to investigate the effect of jolkinolide $B$ on the invasion of MDA-MB-231 cells. As shown in Fig. 3, treatment 

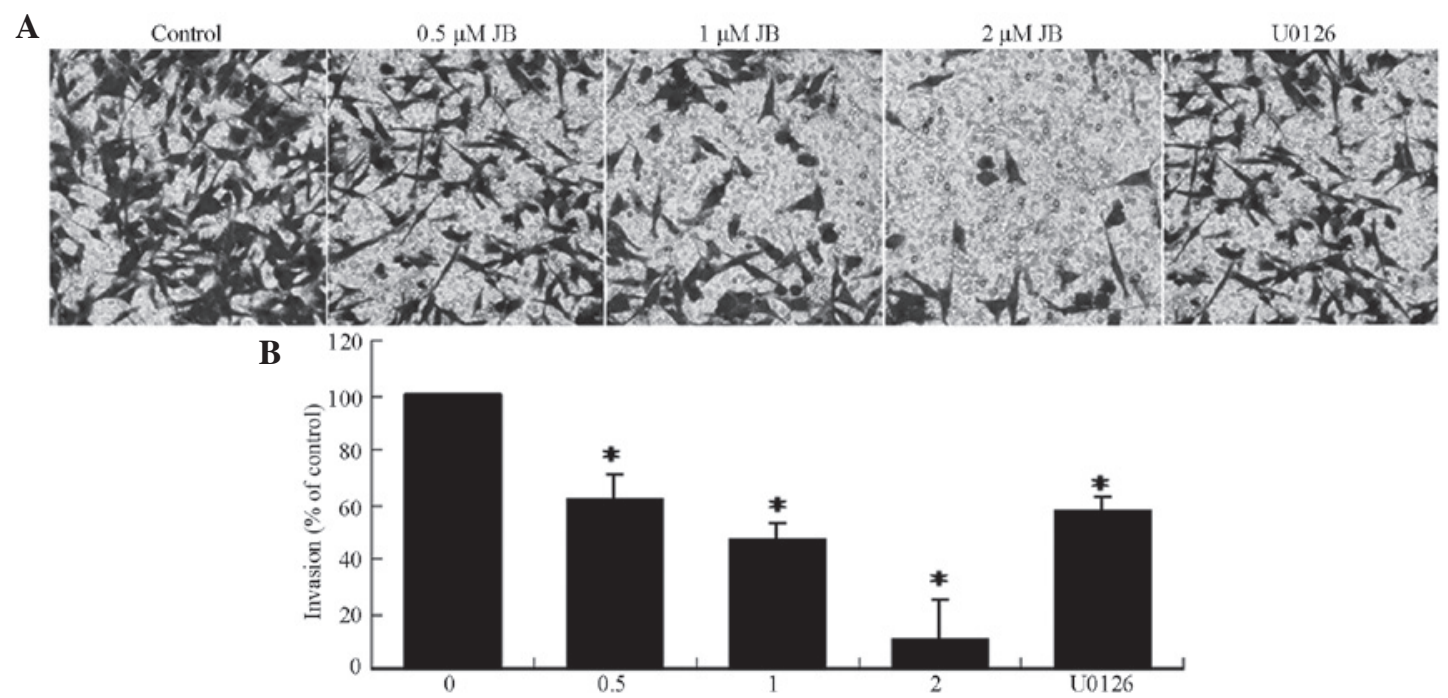

Figure 3. Effect of JB on the invasion of MDA-MB-231 cells. (A) Invasion of cells through reconstituted basement membrane. (B) The number of invaded cells was expressed as the mean \pm standard deviation from three independent experiments. * $\mathrm{P}<0.05$ vs. control group. JB, jolkinolide $\mathrm{B}$.

A

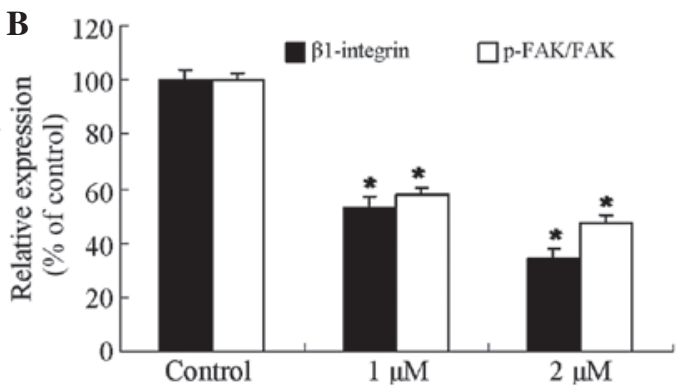

C

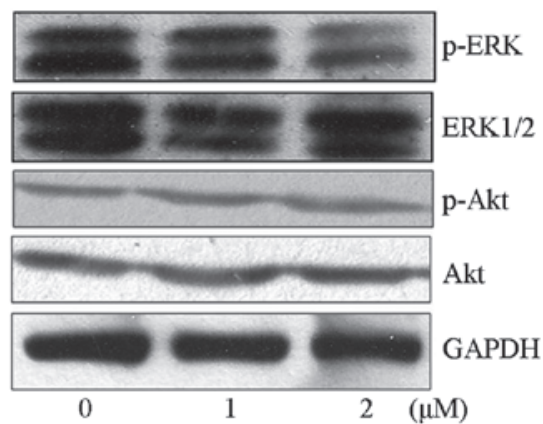

D

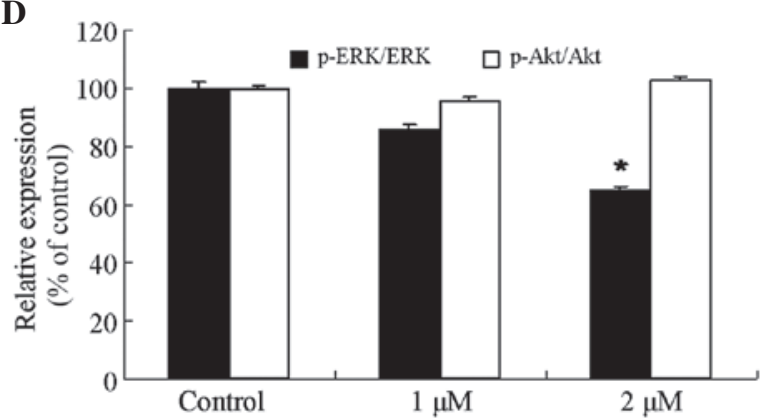

Figure 4. Effect of jolkinolide B on protein expressions of the $\beta_{1}$-integrin/FAK and ERK signaling proteins. (A and B) Effect of jolkinolide B on the expression of the proteins of the $\beta_{1}$-integrin/FAK signaling pathway. Cells were treated with 0,1 and $2 \mu \mathrm{M}$ jolkinolide $\mathrm{B}$. (A) Proteins were extracted, and the expression of $\beta_{1}$-integrin, FAK and p-FAK was then determined by western blot analysis. (B) Densitometric values of protein bands were normalized to those of GAPDH. The data represent the mean $\pm \mathrm{SD}$ of three independent determinations. ${ }^{\mathrm{P}}<0.05$ vs. untreated cells. (C and D) The effect of jolkinolide $\mathrm{B}$ on the expression of ERK signaling proteins. (C) Expression of the ERK signaling proteins in MDA-MB-231 cells was confirmed by western blot analysis. (D) Quantitated results are presented relative to the control. Densitometric analysis of western blotting was obtained from three independent experiments and is expressed as the mean \pm SD. . P $<0.05$ vs. untreated cells. SD, standard deviation; FAK, focal adhesion kinase; p-FAK, phosphorylated FAK; ERK, extracellular signal-regulated kinase; p-ERK, phosphorylated ERK; p-Akt, phosphorylated Akt.

with serial concentrations $(0.5,1$ and $2 \mu \mathrm{M})$ of jolkinolide $\mathrm{B}$ or $10 \mu \mathrm{M}$ U0126 markedly suppressed the invasion activity of MDA-MB-231 cells $(\mathrm{P}<0.05)$.

\section{Effect of jolkinolide B on integrin/FAK and mitogen-activated} protein kinase (MAPK) signaling pathways. As the expression of $\beta_{1}$-integrin was strongly associated with the adhesion of tumor cells, the effect of jolkinolide $B$ on the expression of proteins downstream of $\beta_{1}$-integrin signaling was investigated.
The results demonstrated that treatment of MDA-MB-231 cells with 1 or $2 \mu \mathrm{M}$ jolkinolide $\mathrm{B}$ significantly inhibited the expression of $\beta_{1}$-integrin and phosphorylation of FAK on the Tyr397 site ( $\mathrm{P}<0.05$ vs. control; Fig. $4 \mathrm{~A}$ and $\mathrm{B})$.

MAPK pathways contribute to the invasion and metastasis of cancer (13). To investigate whether the inhibitory effect of jolkinolide B on the adhesion of MDA-MB-231 cells was associated with MAPK signaling, the expression levels and phosphorylation states of extracellular signal-regulated 
kinase (ERK), p38 MAPK, c-Jun N-terminal kinase (JNK) and Akt were measured by western blot analysis. Compared with the untreated cells, the level of ERK phosphorylation in MDA-MB-231 cells treated with $2 \mu \mathrm{M}$ jolkinolide B was significantly inhibited by $61 \%$ (Fig. 4C and D). However, no difference was observed in the expression of $\mathrm{p}$-Akt, phosphorylated JNK or phosphorylated p38 MAPK (data not shown).

\section{Discussion}

The present data demonstrated that jolkinolide $\mathrm{B}$ attenuated the attachment of MDA-MB-231 cells to fibronectin and that these effects are mediated by the integrin/FAK and ERK pathways.

Integrins are a member of the cell adhesion molecule (CAM) family, which mediates the adhesion of tumor cells to the ECM. Cell adhesion mediated by integrins may regulate various cellular functions, including cell proliferation, migration and invasion (12). Activated integrin binds to the ECM, resulting in clustering at the binding site and initiation of focal adhesion by recruitment of crucial cytoplasmic signal transduction proteins, including focal adhesion kinase (FAK) $(14,15)$. FAK is a non-receptor protein tyrosine kinase that plays a key role in the localization of integrin to focal adhesions and in the assembly of integrin signaling molecules (16). Aberrant expression of FAK has been reported in prostate, lung, breast and kidney cancers $(17,18)$. As the activation and expression of integrin and FAK always associate with tumor cell attachment, the expression of $\beta_{1}$-integrin was first tested in eight carcinoma cell lines to explore whether $\beta_{1}$-integrin was involved in cell attachment. The results revealed that $\beta_{1}$-integrin expression varies between the cell lines. Cell lines with higher expression of $\beta_{1}$-integrin, such as the MDA-MB-231 cell line, possessed a stronger adhesion ability compared with cells with lower $\beta_{1}$-integrin expression. However, jolkinolide B markedly inhibited MDA-MB-231 cell adhesion to the ECM.

Jolkinolide B is a diterpenoid compound extracted from the dried plant roots of E. fischeriana Steud that has previously been used to treat edema, ascites and cancers (19). An increasing number of studies indicate that diterpenoids from E. fischeriana Steud, such as 17-hydroxy-jolkinolide B, 17-acetoxyjolkinolide $\mathrm{B}$ and jolkinolide $\mathrm{B}$, are able to induce apoptosis in tumor cells, including human leukemic U937, MDA-MB-231 and HepG2 cells, by modulating the IкB kinase, signal transducer and activator of transcription, or phosphoinositide 3-kinase/Akt pathways (10,20,21). Several studies have also suggested that diterpenoid compounds are able to inhibit cell-ECM adhesion $(13,22)$. Accordingly, the present study hypothesized that, as a diterpenoid compound, jolkinolide B may possess anti-metastasis activity and influence cell-ECM adhesion. In the present study, the effect of the activity of jolkinolide $B$ on cell adhesion to FN was evaluated. The data revealed that jolkinolide $B$ inhibited MDA-MB-231 cell invasion and adhesion to FN in a dose-dependent manner. The anti-adhesion activity of jolkinolide $\mathrm{B}$ involved upregulating the protein expression levels of $\beta_{1}$-integrin. Additionally, the phosphorylation of FAK, a kinase located downstream of $\beta_{1}$-integrin, was blocked by jolkinolide B treatment at the same concentration used to observe anti-adhesion activity. Overall, these results demonstrated that the expression of $\beta_{1}$-integrin may be associated with cell adhesion to FN. Jolkinolide B inhibited cell adhesion to $\mathrm{FN}$ and activation of proteins downstream of $\beta_{1}$-integrin signaling, such as FAK.

Several studies provided clues to explore the potential interaction between integrin and ERK kinase. Activated ERK kinase was involved in Salvicine-induced inhibition of integrin-ligand affinity, downstream phosphorylation of FAK, and integrin-mediated cell adhesion (22). The findings indicated that ERK kinase plays a crucial role in the regulation of cell adhesion and of integrin and FAK function. As such, the effect of MAPK on cell attachment to FN was assessed. Jolkinolide B inhibited the phosphorylation of ERK1/2 at a concentration of $2 \mu \mathrm{M}$ jolkinolide B. The ERK specific inhibitor U0126 also suppressed the adhesion and invasion of MDA-MB-231 cells. These data suggested that ERK kinase is required for jolkinolide B-induced suppression of FAK phosphorylation and may participate in events subsequent to cell adhesion or invasion.

In conclusion, the present results are consistent with the hypothesis that jolkinolide B downregulates FAK phosphorylation and inhibits cell-ECM attachment. The molecular mechanisms underlying the anti-adhesion activity of jolkinolide $\mathrm{B}$ are associated with ERK kinase activity. These findings contribute to the understanding of the mechanisms of jolkinolide $\mathrm{B}$ as a negative regulator in cell attachment to the ECM and may contribute to the development of novel strategies for the treatment of breast cancer metastasis.

\section{Acknowledgements}

This study was supported by the Youth Special Purpose Foundation of Heilongjiang Province (grant no., 1252G004).

\section{References}

1. Pawelek JM and Chakraborty AK: The cancer cell - leukocyte fusion theory of metastasis. Adv Cancer Res 101: 397-444, 2008.

2. Paschos KA, Canovas D and Bird NC: The role of cell adhesion molecules in the progression of colorectal cancer and the development of liver metastasis. Cell Signal 21: 665-674, 2009.

3. Cantor JM, Ginsberg MH and Rose DM: Integrin-associated proteins as potential therapeutic targets. Immunol Rev 223: 236-251, 2008.

4. Cox D, Brennan M and Moran N: Integrins as therapeutic targets: Lessons and opportunities. Nat Rev Drug Discov 9: 804-820, 2010

5. Makrilia N, Kollias A, Manolopoulos L and Syrigos K: Cell adhesion molecules: Role and clinical significance in cancer. Cancer Invest 27: 1023-1037, 2009.

6. Bae YH, Mui KL, Hsu BY, et al: A FAK-Cas-Rac-lamellipodin signaling module transduces extracellular matrix stiffness into mechanosensitive cell cycling. Sci Signal 7: ra57, 2014.

7. Zheng Y and Lu Z: Paradoxical roles of FAK in tumor cell migration and metastasis. Cell Cycle 8: 3474-3479, 2009.

8. Antonyak MA and Cerione RA: Ras and the FAK paradox. Mol Cell 35: 141-142, 2009.

9. Zhao J and Guan JL: Signal transduction by focal adhesion kinase in cancer. Cancer Metastasis Rev 28: 35-49, 2009.

10. Wang JH, Zhou YJ, Bai X and He P: Jolkinolide B from Euphorbia fischeriana Steud induces apoptosis in human leukemic U937 cells through PI3K/Akt and XIAP pathways. Mol Cells 32: 451-457, 2011.

11. Luo $\mathrm{H}$ and Wang A: Induction of apoptosis in K562 cells by jolkinolide B. Can J Physiol Pharmacol 84: 959-965, 2006. 
12. Harjanto D and Zaman MH: Matrix mechanics and receptor-ligand interactions in cell adhesion. Org Biomol Chem 8: 299-304, 2010.

13. Zhu H, Liu XW, Cai TY, et al: Celastrol acts as a potent antimetastatic agent targeting $\beta 1$ integrin and inhibiting cell-extracellular matrix adhesion, in part via the p38 mitogen-activated protein kinase pathway. J Pharmacol Exp Ther 334: 489-499, 2010

14. Berrier AL and Yamada KM: Cell-matrix adhesion. J Cell Physiol 213: 565-573, 2007.

15. Mitra SK and Schlaepfer DD: Integrin-regulated FAK-Src signaling in normal and cancer cells. Curr Opin Cell Biol 18: 516-523, 2006

16. Parsons JT, Slack-Davis J, Tilqhman R and Roberts WG: Focal adhesion kinase: Targeting adhesion signaling pathways for therapeutic intervention. Clin Cancer Res 14: 627-632, 2008.

17. van Nimwegen MJ and van de Water B: Focal adhesion kinase: A potential target in cancer therapy. Biochem Pharmacol 73: $597-609,2007$
18. Golubovskaya VM and Cance W: Focal adhesion kinase and p53 signal transduction pathways in cancer. Front Biosci (Landmark Ed) 15: 901-912, 2010

19. Wang YB, Huang R, Wang HB, Jin HZ, Lou LG and Qin GW: Diterpenoids from the roots of Euphorbia fischeriana. J Nat Prod 69: 967-970, 2006.

20. Wang Y, Ma X, Yan S, Shen S, Zhu H, Gu Y, Wang H, Qin G and Yu Q: 17-hydroxy-jolkinolide B inhibits signal transducers and activators of transcription 3 signaling by covalently cross-linking Janus kinases and induces apoptosis of human cancer cells. Cancer Res 69: 7302-7310, 2009.

21. Yan SS, Li Y, Wang Y, et al: 17-Acetoxyjolkinolide B irreversibly inhibits I $\mathrm{B}$ kinase and induces apoptosis of tumor cells. Mol Cancer Ther 7: 1523-1532, 2008.

22. Zhou J, Chen Y, Lang JY, Lu JJ and Ding J: Salvicine inactivates $\beta 1$ integrin and inhibits adhesion of MDA-MB-435 cells to fibronectin via reactive oxygen species signaling. Mol Cancer Res 6: 194-204, 2008 